\title{
Kalman Filter on Power Electronics and Power Systems Applications
}

\author{
Fernando P. Marafãoํㅣㄹ Diego Colón ${ }^{1}$, Marcelo S. de Padua² \\ and Sigmar M. Deckmann² \\ São Paulo State University ${ }^{1}$, \\ University of Campinas ${ }^{2}$ \\ Brazil
}

\section{Introduction}

For decades, developments have been taking place, separately, in the areas of power systems, digital signal processing and automatic control. Despite of some isolated cases, where the "trajectories" touched, there never was a time when these areas more benefited from each other than in the last few years. Traditionally, power systems problems and applications have been solved by means of purely analog circuits, while an enormous number of digital signal processing and control algorithms have been developed by people working in the communications and control areas. The ever increasing improvement of the semiconductor industry on one hand, and the rising of power electronics applications on the other, have changed this scenario forever, paving the way to the very fruitful area of digital control and signal processing applied on power systems and power electronics. This new area has been applying successfully all the knowledge gathered to improve processes, like power quality monitoring, power system's protection, power conditioning and synchronization of distributed generators (among others), and the most used digital techniques have been digital filtering, discrete Fourier transform, phased-locked loop tracking methods and more recently, the Kalman filtering (Kalman, 1960).

The Kalman filter (KF) was originally proposed to solve a control theoretic problem: considering a linear time-invariant (LTI) system, including state disturbances and measurement errors, how to obtain the best process' LTI state-estimator (in a stochastic sense, that is, minimizing the covariance of the estimation error), in order to be used in a state feedback control law? In conjunction with optimal linear quadratic regulator, the KF found its first application in the well known LQG control (Linear Quadratic Gaussian). After, it became very popular in other areas, according to (Papoulis, 1991), when people became aware of its desirable properties as an estimator. Then several different applications progressively emerged in economics, image processing and biomedical instrumentation, to name a few. More recently, the KF found applications as part of more complex systems, as in an adaptive control system - see for example (Sastry \& Bodson, 1989), where it is shown that the RLS (recursive least mean square) algorithm is a particular case of the KF - and attempts to find a nonlinear KF have been taking place, as in (Wong \& Yau, 1999) and (Colón \& Pait, 2004). 
This chapter presents a concise survey of applications of KF to power systems and power electronics, giving emphasis on the topic of signal's fundamental component identification, which has a key role in most of them. The text is divided as follows: In section two, a review of the fundamental aspects of the KF, as well as a qualitatively explanation of its properties, are given. In section three, a brief description of different applications of the KF is presented. In section four, it is demonstrated how to achieve the fundamental component of measured voltages and/or current signals (their magnitude, frequency and phase angle), independently of input signal distortions or frequency and amplitude deviations. Simulation and experimental results concerning the fundamental component identification are presented in section five. Finally, section six summarizes the main discussions and results presented in this chapter.

\section{Theoretical foundations}

In order to design systems that use the KF, it is important to distinguish between three different concepts: 1) the real process; 2) the state-space mathematical model and 3) the KF itself. The real process can be interpreted as a "black box", producing signals by mean of sensors, which could be disposed in m-dimensional vectors and it could be a power plant or an airplane to be controlled or a signal to be decomposed in harmonics. The state-space mathematical model, on the other hand, is a way to predict the future behaviour of the real process, and consists of a set o first-order (differential or difference) equations, one for each state variable describing its dynamics. This model does not exist physically. Finally, the KF is a system whose objective is to produce on-line estimates for the state-variables, based on on-line measurements of the real process (the outputs). The KF is a system to be implemented digitally.

It is important to note that: 1) the state variables do not necessarily represent a physical quantity and as far as signal processing is concerned, not even one of them does; 2) The KF and the state-space model must be linear time-variant systems, but the KF is a deterministic system, in the sense that all of their inputs are deterministic signals. The state-space model, on the other hand, must have some stochastic inputs to account for the randomness of the real process. In the following, a detailed description of both systems is given. It is supposed also that the process is of discrete-time nature, so only the theory for discrete-time system is considered.

\subsection{Stochastic state-space mathematical models}

The state-space mathematical model must be, as said above, a linear (possibly time-variant) system of the form:

$$
\left\{\begin{array}{ccc}
\boldsymbol{x}(k+1) & = & \boldsymbol{A}(k) \boldsymbol{x}(k)+\boldsymbol{B}(k) \boldsymbol{u}(k)+\boldsymbol{H}(k) \boldsymbol{w}(k) \\
\boldsymbol{y}(k) & = & \boldsymbol{C}(k) \boldsymbol{x}(k)+\boldsymbol{G}(k) \boldsymbol{z}(k)
\end{array}\right.
$$

where $\boldsymbol{x}(k)$ is the n-vector state (containing the n-state variables), $\boldsymbol{y}(k)$ is the output $\mathrm{m}$ vector, $\boldsymbol{u}(k)$ is a deterministic input p-vector signal (control sequence) and $\boldsymbol{w}(k)$ and $\boldsymbol{z}(k)$ are stochastic processes (process noise and measurement noise, respectively), representing, respectively, the uncertainty in the model and in the measurements. The matrices $\boldsymbol{A}(k), \boldsymbol{B}(k), \boldsymbol{C}(k), \boldsymbol{H}(k)$ and $\boldsymbol{G}(k)$ are generally time-invariant and represent the dynamic of 
the process modelled and the noise. The initial state $x(0)=x_{0}$ is a random n-vector uncorrelated to the others $\boldsymbol{w}(k)$ and $\boldsymbol{z}(k)$.

Additional restrictions must be done in the stochastic processes $\boldsymbol{w}(k)$ and $\boldsymbol{z}(k)$ in order to derive a KF, that is, they must be Wide Sense Stationary (WSS) white noise. The mathematical formalism behind stochastic systems, putting altogether, can be a little clumsy. On the other hand, if one works with WSS processes as inputs, and models with matrices varying in a known way, it is easier to cope with. As could be expected, one can only determine statistical parameters of the states/outputs given the statistics of the inputs. In the WSS case, on the other hand, if one knows the input's expected value and autocovariance functions, one can determine the same functions for the states and outputs.

It is a basic result that a sufficiently rich class of spectral power density function can be obtained as the output of a LTI model excited by white noise process. The class of linear time-varying models excited by WSS stochastic process is sufficiently vast to the purposes of this work, as it exhibits sufficient complex correlations between different instants.

\subsection{Kalman filter}

The KF to a state-space model must be a deterministic linear (possibly time-variant) system, as it must be implemented in, for example, a computer, and its inputs must be deterministic signals. The equations for the KF are:

$$
\left\{\begin{array}{ccc}
\widehat{\boldsymbol{x}}(k+1 \mid k) & = & \boldsymbol{A}(k) \widehat{\boldsymbol{x}}(k \mid k-1)+\boldsymbol{B}(k) \boldsymbol{u}(k)+\boldsymbol{K}(k)[\boldsymbol{y}(k)-\boldsymbol{C}(k) \widehat{\boldsymbol{x}}(k \mid k-1)] \\
\widehat{\boldsymbol{y}}(k) & = & \boldsymbol{C}(k) \widehat{\boldsymbol{x}}(k \mid k-1)
\end{array}\right.
$$

where $\widehat{\boldsymbol{x}}(k \mid k-1)$ represents the current state-estimate based in the information collected up to instant $k-1, \widehat{\boldsymbol{y}}(k)$ is the current estimate of the real process output, $\boldsymbol{y}(k)$ is the current real process output and $\boldsymbol{K}(k)$, known as the Kalman open-loop gain, is given by the formula (Davis \& Vinter, 1985):

$$
\boldsymbol{K}(k)=\left[\boldsymbol{A}(k) \boldsymbol{P}(k) \boldsymbol{C}^{T}(k)+\boldsymbol{H}(k) \boldsymbol{G}^{T}(k)\right]\left[\boldsymbol{C}(k) \boldsymbol{P}(k) \boldsymbol{C}^{T}(k)+\boldsymbol{G}(k) \boldsymbol{G}^{T}(k)\right]^{-1}
$$

The matrix $\boldsymbol{P}(k)$ is the estimates' error covariance, given by $\boldsymbol{P}(k)=E[(\boldsymbol{x}(k)-\widehat{\boldsymbol{x}}(k+$ $\left.1 \mid k))(\boldsymbol{x}(k)-\widehat{\boldsymbol{x}}(k+1 \mid k))^{T}\right]$, which can be calculated by the Riccati difference equation:

$$
\begin{aligned}
\boldsymbol{P}(k+1)=\boldsymbol{A}(k) & \boldsymbol{P}(k) \boldsymbol{A}^{T}(k)+\boldsymbol{H}(k) \boldsymbol{H}^{T}(k) \\
& -\left[\boldsymbol{A}(k) \boldsymbol{P}(k) \boldsymbol{C}^{T}(k)+\boldsymbol{H}(k) \boldsymbol{G}^{T}(k)\right]\left[\boldsymbol{C}(k) \boldsymbol{P}(k) \boldsymbol{C}^{T}(k)\right. \\
& \left.+\boldsymbol{G}(k) \boldsymbol{G}^{T}(k)\right]^{-1}\left[\boldsymbol{A}(k) \boldsymbol{P}(k) \boldsymbol{C}^{T}(k)\right. \\
& \left.+\boldsymbol{H}(k) \boldsymbol{G}^{T}(k)\right]^{T}
\end{aligned}
$$

where $\boldsymbol{P}(0)=\boldsymbol{P}_{0}$ is the initial covariance (given by the user).

It can be shown (Davis \& Vinter, 1985) and (Yeh, 1990) that a KF is the best estimator for the states of (1) in the sense of minimum covariance of the estimations and least square estimation.

Some observations are now in order:

I. $\boldsymbol{H}(k) \boldsymbol{H}^{T}(k)$ is the covariance matrix of the process noise and $\boldsymbol{G}(k) \boldsymbol{G}^{T}(k)$ is the covariance matrix of the measurement noise inside the system (not white anymore). Those parameters strongly influence the KF performance in the following way: 1) If the model is known to have more process than measurement noise (that is, $\boldsymbol{G}(k) \boldsymbol{G}^{T}(k)$ is smaller than $\boldsymbol{H}(k) \boldsymbol{H}^{T}(k)$, what makes sense given that both are positive-definite), the 
KF should put more confidence in $\boldsymbol{y}(k)$, what means to have greater $\boldsymbol{K}(k)$. As a consequence, the dynamic response become faster (the bandwidth becomes larger and the filter closed-loop gain tends to one); 2) In the opposite situation, on the other hand, the model output (KF input) is heavily influenced by the measurement noise, and a better result would be achieved giving less weight to $\boldsymbol{y}(k)$, that is, smaller values in the entries of $\boldsymbol{K}(k)$. In consequence, the bandwidth would be narrower and the closed-loop gain less than one. In fact, according to (Yeh, 1990), the Kalman gain can be interpreted as being proportional to the ratio of the norms of $\boldsymbol{G}(k) \boldsymbol{G}^{T}(k)$ over $\boldsymbol{H}(k) \boldsymbol{H}^{T}(k)$. Therefore, the KF design depends on a compromise between desired accuracy and dynamic response, what can be achieved by a proper choice of matrices $\boldsymbol{H}(k)$ and $\boldsymbol{G}(k)$, taking into account input waveform distortions and desired characteristics of final applications.

II. The system in (2) and (3) is to be implemented in a digital processor, and calculates the state-estimates recursively and on-line, as it depends on the current output of the process. The equation (4), however, could be solved off-line, that is, before the KF starts to "filter", if the values of the model's matrices are known in advance. This implementation significantly reduces the memory and CPU time needed in digital systems, what is essential in practical applications.

III. Independently of its final use, which can be either on open or closed-loop applications, the KF is itself a closed-loop system, in the sense that the estimation $\widehat{\boldsymbol{y}}(k)$ generated is constantly compared to the real signal $\boldsymbol{y}(k)$ and the discrepancy is used in calculating the future estimates. Also, the optimality guarantees robustness and stability.

IV. Substituting (3) in (4), it is easy to see that the equation (4) could be restated in the form

$$
\begin{aligned}
\boldsymbol{P}(k+1)= & \boldsymbol{A}(k) \boldsymbol{P}(k) \boldsymbol{A}^{T}(k)+\boldsymbol{C}(k) \boldsymbol{C}^{T}(k) \\
& -\boldsymbol{K}(k)\left[\boldsymbol{A}(k) \boldsymbol{P}(k) \boldsymbol{C}^{T}(k)+\boldsymbol{H}(k) \boldsymbol{G}^{T}(k)\right]^{T}
\end{aligned}
$$

V. The optimality of the KF is guaranteed under the hypothesis of (uncorrelated) Gaussian white noise $\boldsymbol{w}(k)$ and $\boldsymbol{z}(k)$. Of course, some modifications in the covariance matrices can change the spectral power density in order to produce the kind of correlation necessary to turn the KF optimal in these cases.

VI. In case of all the matrices being time-invariant (that is, LTI model), it is expected that, after the transient, the estimation process would result in more accurate results than in the beginning, as the process reaches a stationary condition. In fact, equation (4) is deterministic and tends to stabilize in a final value.

\section{KF on power electronics and power systems - state of the art}

A concise description of different applications of the KF in power electronics and power systems areas is summarized in next sections. Even if some of them have been proposed more than 20 years ago, especially those based on off-line processing, the applications are quite limited if compared with other digital techniques applied in such areas. Probably, it happened because of the computational complexity of the KF for on-line applications that could not have the equation (4) solved off-line (for example, when the model's matrices change in not a priori known pattern).

Nevertheless, considering the ever increasing capacity of digital processor's technology, this line has been broken down and new KF applications have emerged, including on-line approaches. Most of them are based on the identification of the fundamental $60 \mathrm{~Hz}$ 
components $\left(x_{1}\right)$ of phase voltages and/or currents (amplitude, phase and frequency) or even based on the fundamental positive sequence components $\left(x_{1}^{+}\right)$.

\subsection{Load forecasting and modal estimation}

One of the first applications of the KF in the power system area had been to forecast the total load demanded by a multi-node system (Abu-El-Magd et al., 1981; Park et al., 1991). Temporal load data, collected by the various agents in the power system administration, are used in order to predict load conditions, and the KF is frequently a fundamental part of the algorithm. Normally, the collected data are hourly based, and the prediction algorithm must yield short-term results, that would be useful in scheduling the actual system in order to supply the daily demand, and medium and long-term results, what would be useful in, for example, expansion planning and annual maintenance scheduling. Load forecasting has been gaining more importance as long as the electricity market becomes deregulated and the power sources become more and more distributed in the interconnected grid (Song et al., 2006).

In this kind of application, there is not much difference from the forecasting of economic data, as presented in (Clements \& Hendry, 1998). There is a temporal series of power consumption and several periodicities and trends can be detected. The most evident is the daily periodicity on weekdays, which assumes the peak value around the beginning of the night. On Sundays and holydays, however, the pattern consumption tends to be less correlated. This pattern also reveals a weekly and monthly periodicity, and a yearly periodicity can obviously be assumed. Trends are always present in this kind of data, and the most important is the rising consumption that can be observed in the series. It is also important to mention the parameter dependence variations coming from the climate (mostly temperature). In tropical countries, the load is expected to be higher in summer, by the use of air conditioning systems, for example.

On the technical side, it is always possible to associate to a temporal series a model like (1), where $\boldsymbol{y}(k)$ is the series itself. The states, on the other hand, could be the periodic components (in a Fourier series sense) or even non-periodic, and the matrices could be determined in order to generate those components (obviously time-invariant in this case). Disturbances and noise covariance should be adequately selected. The KF would act in order to estimate those components, which would be the states and could represent trends and seasonal behaviour. The matrices could even be time-varying, if the process is known to be more complex.

In a similar way, other interesting application is the modal estimation of the power system. Based on power system's measurements under normal conditions and defining a stochastic model relating different disturbance inputs (e.g., load changes), the KF is adjusted to estimate the outputs produced by the disturbances. Then, by monitoring the difference between the measured output and the estimated output, one can recognize if there is any change in the model parameters (Wiltshire et al., 2007).

\subsection{Protection and digital relaying}

Other key application of KF in power systems is to detect fault conditions and to control protection devices, a task normally done by digital relays. Based on information coming from voltages and currents, decisions must be taken in order to detect and protect the power system from more severe faults and maintain its stable operation (Girgis \& Brown, 1981). 
The discrete signals coming from several sensors do contain valuable information, but it is necessary to extract it from input disturbances, what means that it is necessary to identify the signals fundamental component $\left(v_{1}\right)$, given that during transient conditions the fundamental voltages or currents are corrupted (Girgis, 1982; Mir \& McCleer, 1984; Sachdev et al., 1985).

Of course, this information is in the transient condition and depending on the kind, frequency of occurrence and location of the fault, the effects produced in the $60 \mathrm{~Hz}$ components (and other frequencies), are of very particular type, allowing gathering valuable information in order to control a protective device or to plan a repair as soon as possible.

\subsection{Analysis and control of electrical machinery}

Considering the digital control or analysis of induction motors, the KF has been applied in some different ways, e.g., to estimate the rotor time constant in PWM motor drives (Zai et al., 1992); to estimate the airgap flux in order to implement a direct flux control strategy (Pietrzak-David et al., 1992) or also to identify the rotor resistance in order to propose adaptive vector control schemes (Wade et al., 1997). In addition, KF has been also applied in order to reduce or avoid the use of additional sensors in the motor controlling or monitoring, considering the so called sensorless applications (Bolognani et al., 2001).

It is interesting to mention that these applications use the KF as part of an automatic closedloop control system, that is, in the same way as its first applications (see section 1). Conversely, in the others mentioned in sections 3.1 and 3.2, the information from the estimates was used by people in decision making processes or open-loop applications.

\subsection{Power conditioners control and synchronization}

The requirement of synchronization of several electronic devices (such as active rectifiers, active power filters, uninterruptible power suppliers, dynamic voltage restorers, distributed generators, etc.) has been motivating the development of different algorithms to detect the amplitude, frequency and phase angle of the power grid fundamental voltage (Padua et al., 2007; Moreno et al., 2007). Such required information can be provided by the KF output (Padua et al., 2007a; Cardoso, et al., 2007; Huang et al., 2008), as it will be demonstrated in the following.

In the matter of power conditioning, several closed-loop control schemes have been applied in order to control the voltages and currents waveforms, frequency, and amplitudes of an electrical load or point of common coupling (PCC) (Peng, 2001). Many control laws can be used in order to guarantee the voltage/current to track the references, and to compensate for disturbances, running from classically inspired techniques (Marafão et al., 2008) to those including a KF in the control loop (Moreno et al., 2004; Kwan et al., 2005; Rosendo et al, 2007).

An active rectifier, e.g., should drain a sinusoidal current from the supply system, which should be in-phase with the fundamental component of the grid voltage, even if this one is distorted. This will ensure a high power factor for the resulting active rectifier. In case of three-phase devices, it is also desired to ensure equal phase currents, it means that the threephase rectifier will act as resistive balanced load.

An active power filter, either in series or parallel to the loads, should ensure, e.g., that voltages and/or currents (depending of the configuration) are sinusoidal, balanced, symmetrical and with constant magnitude. It is possibly based on the identification of the 
disturbing signals, which will become the references for the control scheme in order to be injected in or filtered out of the power system. In this case, the KF should be responsible for the detection of the ideal signals (fundamental positive sequence components $x_{1}^{+}$) and by the difference with the original voltages or currents, the deteriorated signals (harmonic distortions, voltage sags and swells, low power factor, unbalances, etc.) could be identified $\left(x_{d}=x-x_{1}^{+}\right)$.

In the matter of distributed generation, the control of different power sources (AC or DC) have been carried out by means of electronic power converters and usually, it depends on some synchronized signal, in order to ensure that the generated voltages have the same frequency and phase angle of the main power grid (Padua et al., 2007). Again in this case, the required information could be achieved by means of the KF.

\subsection{Revenue metering and power quality monitoring}

The continuously increasing demand for electronic equipments and power converter applications has been the most important cause of power quality deterioration phenomena, including voltage and current distortions and imbalances. The impacts of such disturbing effects can be directly related to power losses, insulation stress, over voltages, power oscillations or even malfunction and damage on sensitive loads (Bollen, 2000).

Among a number of different areas related to this question, during the last decades intensive research has been directed to the definition of power quality indices and revenue metering techniques, suitable for monitoring nonlinear and unbalanced systems (Ferrero et al, 1998; Marafão et al., 2002; Farghal et al, 2002).

Considering the power quality monitoring, important indices have been defined to estimate the amount of harmonic distortion or unbalances on the measured voltage $(v)$ and currents (i) or also how these distortions affect other indicators, such as, e.g., the power factor $(P F)$. Once more, the KF can be applied in order to identify the fundamental components $\left(v_{1}, i_{1}\right)$ and the positive sequence components $\left(v_{1}^{+}, i_{1}^{+}\right)$, which could be used to the calculation of the mentioned indices. Thus, indices such as: the voltage Total Harmonic Distortion $T H D_{V}=\frac{\sqrt{\sum_{h=2}^{N} V_{h}^{2}}}{V_{1}}$ or Negative Unbalance Factor $K^{-}=\frac{V_{1}^{-}}{V_{1}^{+}}$are defined.

In the matter of revenue metering, considering for example the IEEE STD 1459-2000, which brings the definition of several power quantities related to fundamental components, positive sequence components, harmonic components, among others, the KF application could be responsible for the calculation of, e.g., the Fundamental Active Power $\left(P_{1}\right)$, the Fundamental Equivalent Apparent Power $\left(S_{e 1}\right)$, the Fundamental Power Factor $\left(F P_{1}\right)$, the Fundamental Positive Sequence Power Factor $\left(F P_{1}^{+}\right)$.

The KF has also been applied to the development of expert systems focused on the analysis, classification and possible cause's identification of short term power quality disturbances, such as: voltage sags, swells and interruptions (Styvaktakis et al., 2002; Dash \& Chilukuri, 2004; González et al., 2006).

\section{Fundamental component identification}

As stated in the above section, in many power system and power electronics' applications, it is necessary to identify the fundamental component of voltages and/or currents signals, independently of frequency fluctuations, amplitude variations and waveform distortions. 
phase-locked loop (PLL) has been one of the most applied algorithms to get the required information (Kaura \& Blasko, 1997; Zhan et al, 2001; Padua et al, 2005). Recent researches, however, have shown that recursive discrete Fourier transform (RDFT) could also be applied (Andria \& Salvatore, 1990; McGrath et al., 2005). Other possibility is the KF. All of the mentioned techniques can be used in single-phase systems. Moreover, the PLL and KF can also be applied in three-phase systems with a suitable model (Padua et al., 2007; Moreno et al., 2007).

In the following sections, two distinct ways of using the KF in fundamental component identification are presented. One method uses a second order KF, treating all the signal components as disturbances (except for the fundamental). The other uses a $2 \mathrm{n}$-order KF, and includes the harmonics in the deterministic part of the model (Cardoso et al., 2006; Mustafa, 2007). It can be shown that the last KF represents a great computational burden, and the performance of both, as long as fundamental component identification is concerned, is very similar. The first section presents both KF for the single-phase case, and the following section presents the three-phase case.

\subsection{Single-phase case}

The filter design begins with determining a state-space model to the real signal to be measured, including the fundamental component, harmonics, inter-harmonics, and other disturbances. In stationary regime, the harmonic of order $i$ of a (voltage) signal (with $\mathrm{N}$ samples per period) is given by

$$
v_{i}(k)=V_{i} \sin \left[\frac{2 \pi k i}{N}+\theta_{i}\right]
$$

where $V_{i}$ is the fundamental amplitude, $\theta_{i}$ is the phase angle and $N=f_{s} / f_{1}$, that is, the number of samples in the fundamental component. By using the values of this sequence in successive steps, one can show, by basic trigonometric properties, that

$$
v_{i}(k)=v_{i}(k-1) \cos \frac{2 \pi i}{N}-v_{i}^{q}(\mathrm{k}-1) \sin \frac{2 \pi i}{N}
$$

The signal $v_{i}^{q}(k)$ is known as the in quadrature component and is orthogonal to $v_{i}(k)$. Searching for a similar identity for $v_{i}^{q}(k)$, it is possible to write down a recursive formula for both components in a vector form. By defining the vector $\boldsymbol{V}_{\boldsymbol{i}}(k)=\left[\begin{array}{ll}v_{i}(k) & v_{i}^{q}(k)\end{array}\right]^{T}$, the formula becomes:

$$
\begin{gathered}
\boldsymbol{V}_{\boldsymbol{i}}(k)=\boldsymbol{A}_{\boldsymbol{i}} \cdot \boldsymbol{V}_{\boldsymbol{i}}(k-1) \text {, where the matrix } \boldsymbol{A}_{\boldsymbol{i}} \text { is given by } \\
\qquad \boldsymbol{A}_{\boldsymbol{i}}=\left[\begin{array}{rr}
\cos \frac{2 \pi i}{N} & -\sin \frac{2 \pi i}{N} \\
\sin \frac{2 \pi i}{N} & \cos \frac{2 \pi i}{N}
\end{array}\right]
\end{gathered}
$$

The formula above represents a dynamical state-variable model of a harmonic of order $i$ and could be used, in combination with other similar systems, to represent a periodic signal, (with harmonics till order $n$ ), which would have a matrix of the form: 


$$
\mathrm{A}=\left[\begin{array}{ccc}
\boldsymbol{A}_{1} & \cdots & 0 \\
\vdots & \ddots & \vdots \\
0 & \cdots & \boldsymbol{A}_{n}
\end{array}\right]
$$

The state-vector would have the form $\boldsymbol{V}(k)=\left[\begin{array}{lll}\boldsymbol{V}_{\mathbf{1}} & \ldots & \boldsymbol{V}_{\boldsymbol{n}}\end{array}\right]^{\mathrm{T}}$, and the fundamental component of periodic signal would be given by

$$
v(k)=\left[\begin{array}{llllll}
1 & 0 & 0 & \ldots & 0 & 0
\end{array}\right] \cdot \boldsymbol{V}(k)=\boldsymbol{C} \cdot \boldsymbol{V}(k)
$$

In order to represent the disturbances (all the components other than the harmonics till order $\mathrm{n}$ ) and the measurement noise and errors (for example, the quantization noise), process and measurement noise should be added, which put the model in the form presented in (1), but with null exogenous control input $\boldsymbol{B}(k)=0$. Thus, the complete signal model is:

$$
\left\{\begin{array}{ccc}
\boldsymbol{V}(k+1) & = & \boldsymbol{A}(k) \cdot \boldsymbol{V}(k)+\boldsymbol{H} \cdot \boldsymbol{w}(k) \\
v(k) & =\boldsymbol{C} \cdot \boldsymbol{V}(k)+\boldsymbol{G} \cdot \boldsymbol{z}(k)
\end{array}\right.
$$

All the matrices in the model, except $\boldsymbol{A}(k)$, do not vary with time, and $\boldsymbol{H}$ and $\boldsymbol{G}$ are related to the covariance matrices of the process and measurement noises, that could be conveniently chosen if a priori information about the nature of the disturbances is available. The model to be used in case of complete lack of prior information is Gaussian white noise, and both matrices would be proportional to the identity matrix.

Having the estimates coming from the $\mathrm{KF}$, it is possible to calculate the fundamental component's magnitude and phase, by the formulas:

$$
M=\sqrt{\hat{v}_{1}^{2}(k)+\left(\hat{v}_{1}^{q}(k)\right)^{2}}
$$

and

$$
\theta(k)=\tan ^{-1}\left[\frac{\hat{v}_{1}(k)}{\hat{v}_{1}^{q}(k)}\right]
$$

and the fundamental frequency $f_{1}$ can be estimated from zero-crossing detection of the signal $\theta(k)$ and improved with an average of the last four estimates.

In these applications, if the sample frequency $f_{s}$ is kept constant, the $\boldsymbol{A}(k)$ matrix must be varied according to the most recent estimation of $f_{1}$. It means that the difference Riccati equation have to be solved on-line. Of course, the greater the number of harmonics represented in the $\boldsymbol{A}$ matrix, the greater the computational burden.

A more attractive alternative, as presented in (Padua et al, 2007), is to consider only the fundamental component in the $\boldsymbol{A}(k)$ matrix, and by choosing $\boldsymbol{H}$ and $\boldsymbol{G}$ adequately, the other harmonics would be represented in the noise models. The performance of this simplified model is as good as in the first case, and the computational burden is significantly reduced. In section 5, simulation and experimental results for this case are presented.

Another possible alternative can be applied if the sampling frequency were a free parameter, it means, if it were possible to change its value on-line, in order to ensure a fixed number of samples regarding to the fundamental component $(\mathrm{N})$. 


\subsection{Three-phase case}

In the same spirit of the single-phase model, a set of three-phase fundamental voltages can also be represented by means of a state space model of the form (1), but where the matrix $\boldsymbol{A}$ is given by:

$$
A=\left[\begin{array}{cccc}
\cos \left(\frac{2 \pi}{N}\right) & \frac{1}{\sqrt{3}} \sin \left(\frac{2 \pi}{N}\right) & -\frac{1}{\sqrt{3}} \sin \left(\frac{2 \pi}{N}\right) & 0 \\
-\frac{1}{\sqrt{3}} \sin \left(\frac{2 \pi}{N}\right) & \cos \left(\frac{2 \pi}{N}\right) & \frac{1}{\sqrt{3}} \sin \left(\frac{2 \pi}{N}\right) & 0 \\
\frac{1}{\sqrt{3}} \sin \left(\frac{2 \pi}{N}\right) & -\frac{1}{\sqrt{3}} \sin \left(\frac{2 \pi}{N}\right) & \cos \left(\frac{2 \pi}{N}\right) & 0 \\
\sin \left(\frac{2 \pi}{N}\right) & 0 & 0 & \cos \left(\frac{2 \pi}{N}\right)
\end{array}\right]
$$

And the state vector is given by $\boldsymbol{V}(k)=\left[\begin{array}{llll}\boldsymbol{v}_{\boldsymbol{a} \mathbf{1}}(k) & \boldsymbol{v}_{\boldsymbol{b} \mathbf{1}}(k) & \boldsymbol{v}_{\boldsymbol{c} \mathbf{1}}(k) & \boldsymbol{v}_{\boldsymbol{a} \mathbf{1}}^{\boldsymbol{q}}(k)\end{array}\right]^{\boldsymbol{T}}$, where the first three components are three-phase signals and the last component is orthogonal to the first. The matrix $\boldsymbol{C}$, that represents the output of the model, that is, the three-phase components, is given by:

$$
\boldsymbol{C}=\left[\begin{array}{llll}
1 & 0 & 0 & 0 \\
0 & 1 & 0 & 0 \\
0 & 0 & 1 & 0
\end{array}\right]
$$

The signals $\boldsymbol{w}(k)$ and $\boldsymbol{z}(k)$ are Gaussian white noise vectors, as expected, and represents the distortions. The instantaneous phase angle can thus be obtained by:

$$
\theta(k)=\tan ^{-1}\left[\frac{\hat{v}_{a 1}(k)}{\hat{v}_{a 1}^{q}(k)}\right]
$$

and the fundamental frequency $f_{1}$ can be calculated in the same way as in the simplified single-phase model. In case of unbalanced (amplitudes), but symmetrical (phase angle) input voltages, such KF model has the advantage to be able to identify the positive sequence component, in such a way that its magnitude can be calculated by:

$$
V^{+}(k)=\sqrt{\frac{2}{3}\left[\hat{v}_{a 1}^{2}(k)+\hat{v}_{b 1}^{2}(k)+\hat{v}_{c 1}^{2}(k)\right]}
$$

In addition, it has been verified that if $\boldsymbol{H}$ and $\boldsymbol{G}$ were set to attenuating harmonic distortions, the dynamic convergence of the three-phase model is better than the single-phase one, since, statistically, its model has more information than the previous. However, it should be considered that its implementation complexity is also superior $(4 \times 4$ systems instead of $2 \times 2)$.

\section{Simulation and experimental results}

\subsection{Simulation results}

In order to compare different KF's for the same application, some simulations were realized and the results are presented in the sequel. The sampling frequency $f_{s}$ was chosen to be 12 $\mathrm{kHz}$, what means that the number of samples per period $\mathrm{N}$ varies with $f_{1}\left(\mathrm{~N}=200\right.$ for $f_{1}=60$ $\mathrm{Hz}$ ). In order to find the ideal balance between velocity of response and filtering quality, different matrices $G G^{T}(k)$ and $H H^{T}(k)$ were tested. Considering adequate results for both, the filtering and dynamic response, appropriate values were defined as, for the single-phase system: 


$$
G G^{T}=\left[\begin{array}{cc}
0.01 & 0 \\
0 & 0.01
\end{array}\right] \text { e } H H^{T}=[25],
$$

and for the three-phase system:

$$
G G^{T}=\left[\begin{array}{cccc}
0.0025 & 0 & 0 & 0 \\
0 & 0.0025 & 0 & 0 \\
0 & 0 & 0.0025 & 0 \\
0 & 0 & 0 & 0.0025
\end{array}\right] \text { e } H H^{T}=\left[\begin{array}{ccc}
16 & 0 & 0 \\
0 & 16 & 0 \\
0 & 0 & 16
\end{array}\right],
$$

These values were found following the suggestion of (Simon, 2001) and references therein. Note that the entries of $H H^{T}(k)$ are much greater than the ones in $G G^{T}(k)$, what is the way to attenuate the harmonic distortion.

It is worth mentioning that in order to guarantee the same performance, different values of these matrices must be used for different voltage levels.

\subsubsection{Single-phase case}

In order to evaluate the performance of the simplified single-phase KF on the fundamental component identification, four different input voltage conditions were simulated:

Case 1 - Sinusoidal $60 \mathrm{~Hz}$ voltage with amplitude equal to $127 \mathrm{Vrms}$ and $90^{\circ}$ phase angle;

Case 2 - The same conditions of Case 1, but with the addition of $5 \%$ of harmonic distortion in each 3rd, 5th and 7th harmonics;

Case 3 - The same conditions of Case 2, but with a voltage sag of $50 \%$;

Case 4 - The same conditions of Case 2, but with the addition of an abrupt frequency transition from $60 \mathrm{~Hz}$ to $59 \mathrm{~Hz}$.

Fig. 1 shows the influence of the initial state of the filter, which must be set by the user. In this case, values were chosen such that the initial phase of the signal should be $0^{\circ}$. In the uppermost graphic, the sinusoidal voltage $v$ (output of the KF) along with their in-phase $(v 1)$ and orthogonal $(v q)$ components are presented. Note that the convergence is achieved in about six cycles. In the bottom graphic, the fundamental frequency $f_{1}$ calculated as indicated earlier, converges to $60 \mathrm{~Hz}$. The observed transient comes from the difference between the real state of the system $(\theta=909)$ and the one fixed in the algorithm $(\theta=0)$. Just for comparison, in Fig. 2 the initial phase angle was set to $(\theta=0)$, as the KF initial state definition. It is obvious that the closer the initial value to the real phase, the faster the convergence. Observe that the convergence in this case is achieved in less than 3 cicles.

The good filtering performance of KF-1 $\phi$ can be observed in Fig. 3 (Case 2). The Total Harmonic Distortion (THD), which would be $8.66 \%$ in the modelled signal $(v)$, was reduced to about $1 \%$ in the fundamental output $(v 1)$.

Figs. 4 e 5 show the performance of KF-1 $\phi$ when there are abrupt transitions in amplitude and frequency. In the first case, estimated voltages converge in less than 2 cycles, while fundamental frequency estimate practically does not change. In the second case, $v 1$ and $v q$ follow $v$ while $f_{1}$ stabilizes in 9 cycles. Little ripple in frequency $(58.90 \mathrm{~Hz}-59.04 \mathrm{~Hz})$ can be observed as the ratio $f_{S} / f_{1}$ is no longer an integer number. If necessary, such frequency ripple could be minimized updating the matrix $\mathrm{A}$ or the sampling frequency in order to maintain a fixed number of samples per fundamental period $(\mathrm{N})$. 

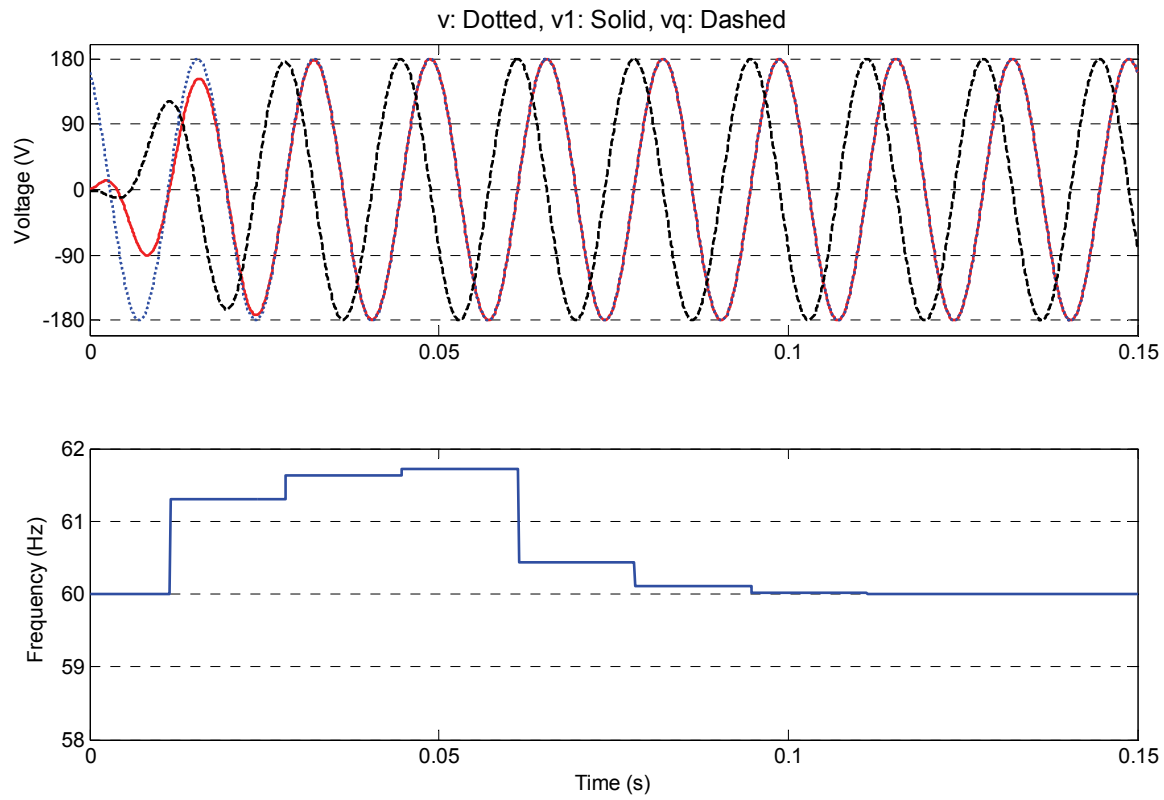

Fig. 1. KF-1 $\phi$ (Case 1): Input voltages $\left(127 \mathrm{Vrms}, 60 \mathrm{~Hz}, 9^{\circ}\right)$ and filter outputs: v1, vq e $f_{1}$.
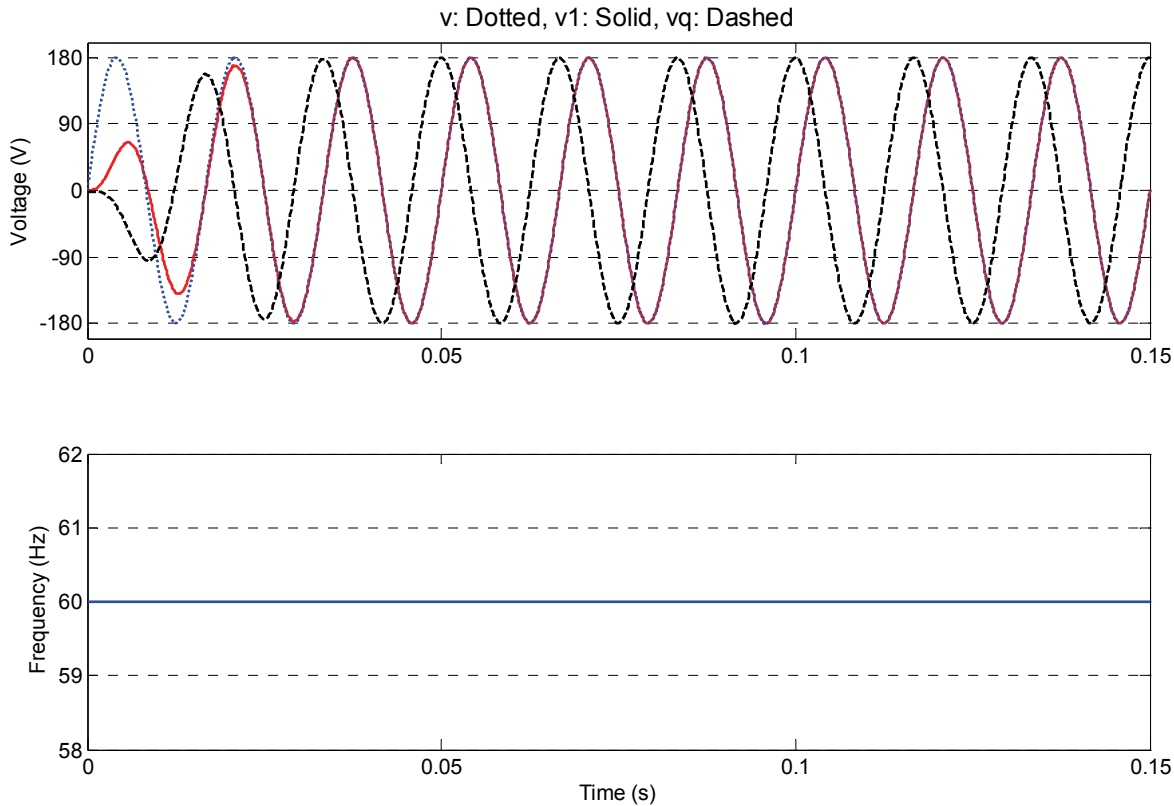

Fig. 2. KF-1 $\phi$ (Case 1): Input voltages $\left(127 \mathrm{Vrms}, 60 \mathrm{~Hz}, 0^{\circ}\right)$ and filter outputs: v1, vq e $f_{1}$. 

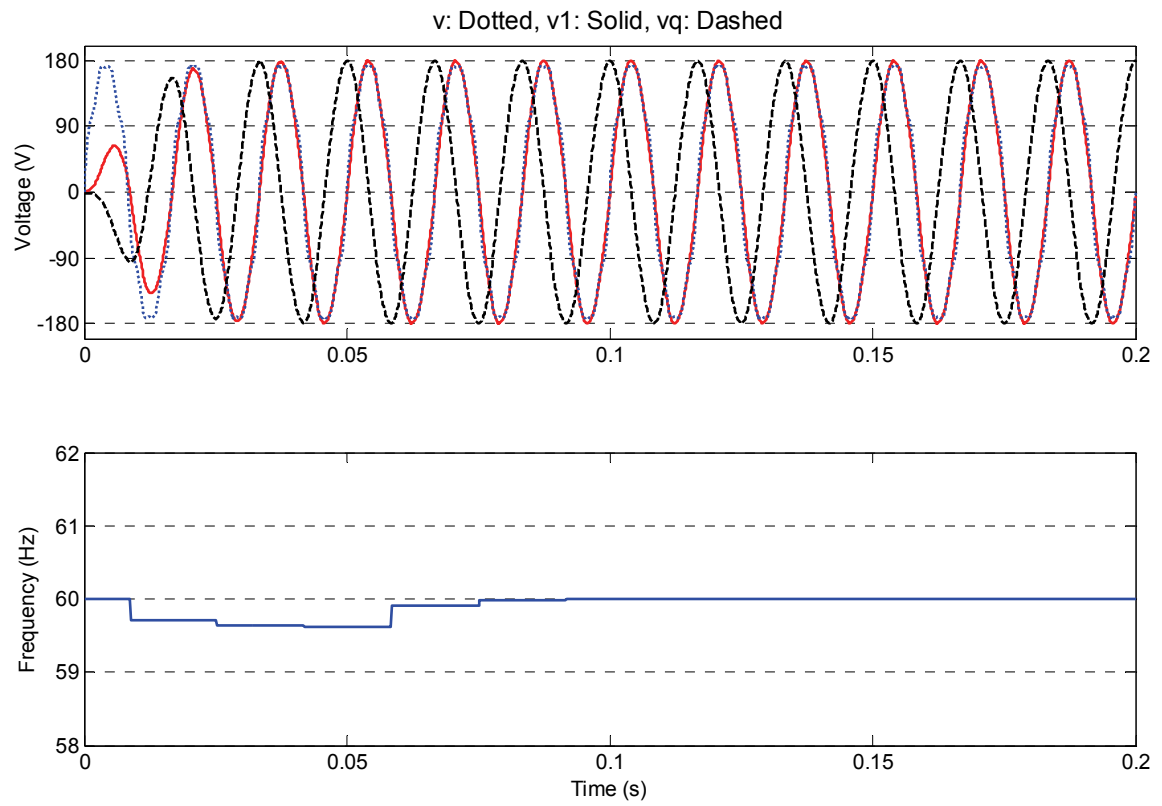

Fig. 3. KF-1 $\phi$ (Case 2$)$ : Input voltage $\left(127 \mathrm{Vrms}, 60 \mathrm{~Hz}, 0^{\circ}\right)$, with $5 \%$ of distortion in $3^{\text {rd }}, 5^{\text {th }}$ and $7^{\text {th }}$ harmonics and filter outputs: v1, vq e $f_{1}$.
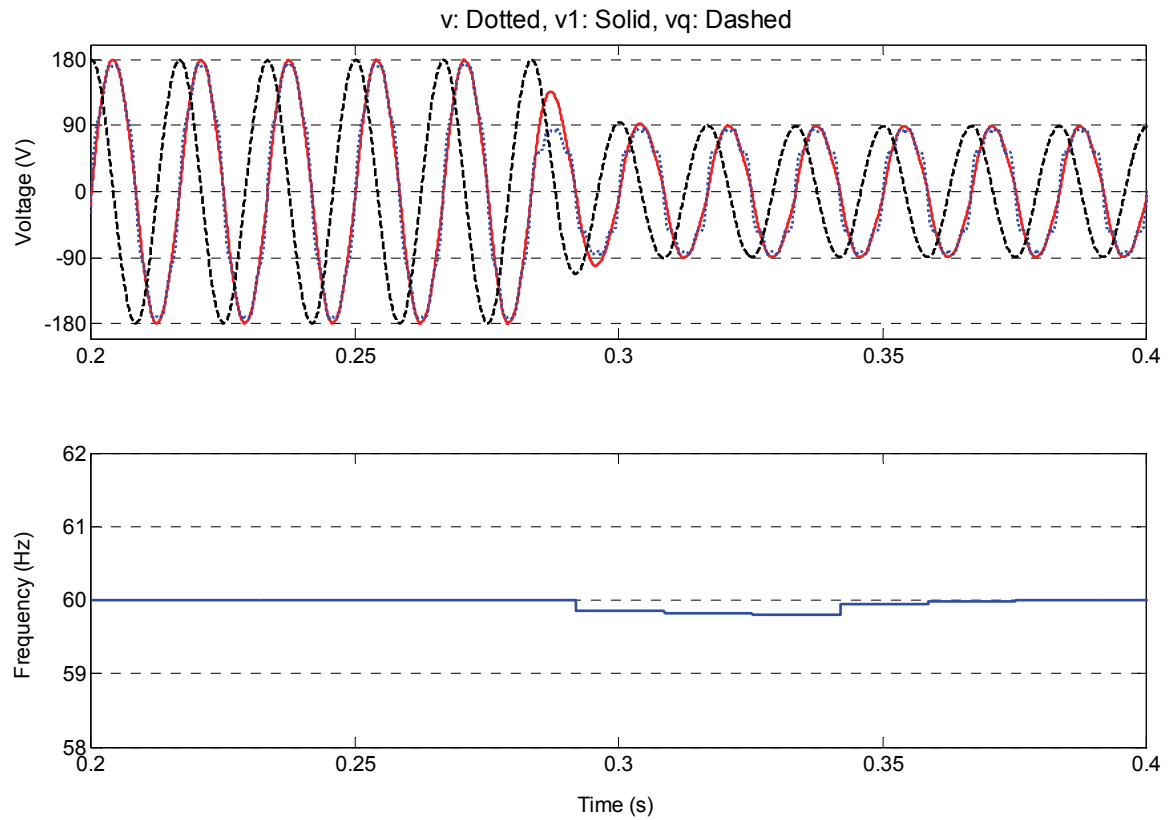

Fig. 4. KF-1 $\phi$ (Case 3): Input voltage and filter outputs: v1, vq e $f_{1}$, after a voltage sag. 

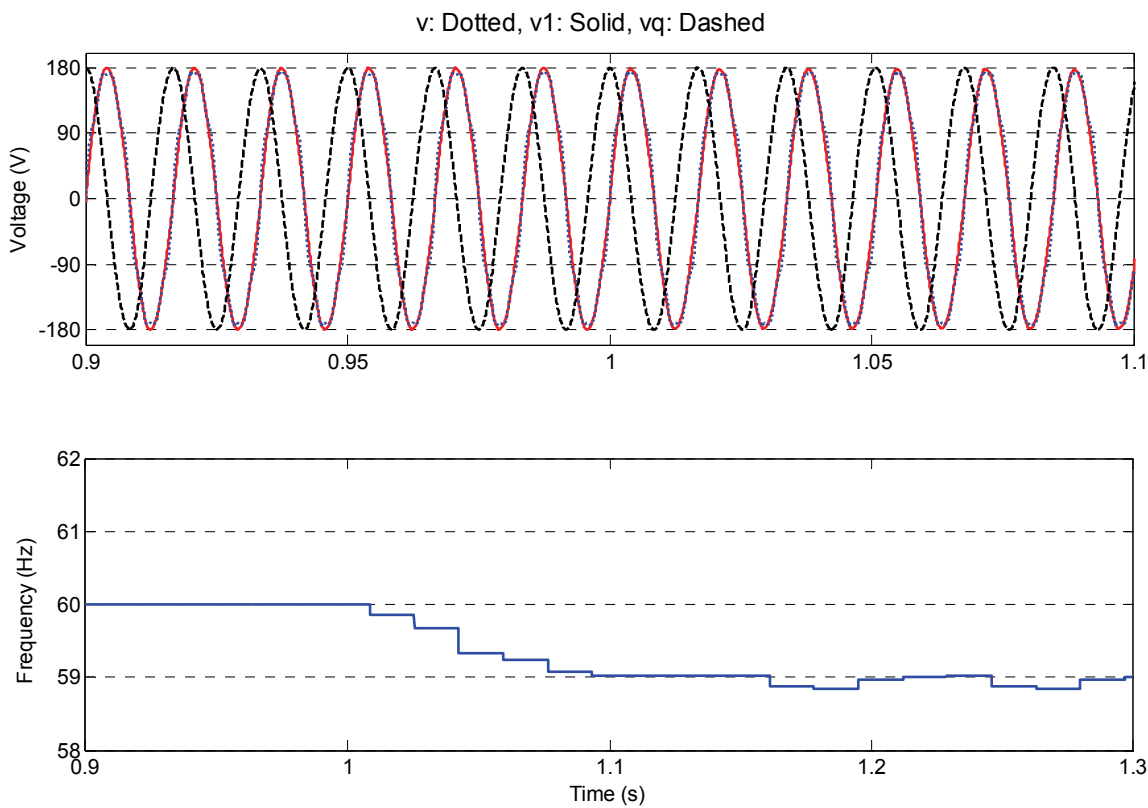

Fig. 5. KF-1 $\phi$ (Case 4): Input voltage and filter outputs: v1, vq e $f_{1}$, after a frequency transient.

\subsubsection{Three-phase case}

In the same way of the previous section, four different conditions were imposed to the threephase KF in order to evaluate its performance. The results are discussed in the following.

Case 1 - Sinusoidal and balanced $(60 \mathrm{~Hz}, 127 \mathrm{Vrms})$ three-phase voltages, with $\theta a=0^{\circ}$ (initial phase-a angle);

Case 2 - Unbalanced voltages $\left(70 \%\right.$ in phase $\mathrm{b}$ and $85 \%$ in phase c), with $5 \%$ of $3^{\text {rd }} 5^{\text {th }}$ and 7 th harmonic distortion;

Case 3 - The same conditions of Case 2, but with a voltage sag of $50 \%$;

Case 4 - The same conditions of Case 2, but with the addition of an abrupt frequency transition from $60 \mathrm{~Hz}$ to $59 \mathrm{~Hz}$.

Fig. 6 shows the fast dynamic response of the KF-3 $\phi$ outputs considering Case 1. In the central graphic, the sinusoidal phase voltage (va) and its fundamental component (va1), that comes from the KF are put together. One can see the convergence in less than 2 cycles. In the bottom, the left graphic indicates the evolution of the positive sequence magnitude (Seq+) and the right-side graphic shows the fundamental frequency convergence.

In Fig. 7, a case with unbalanced and distorted (THD=8.66\%) three-phase voltages is analyzed. Once more, one can see the convergence in about 2 cycles (with the same initial state in the KF) and the good filtering behaviour of the KF (fundamental output with a distortion reduction to $\mathrm{THD}=0.8 \%$ ). Besides, the amplitudes of va1 and of the others resulting fundamental components are equal to $179,6 \times(1+0,7+0,85) / 3 \cong 152,66 \mathrm{~V}$, what is the mean value of the measured amplitudes, which in this case, coincides with the positive sequence magnitude (Seq+). 

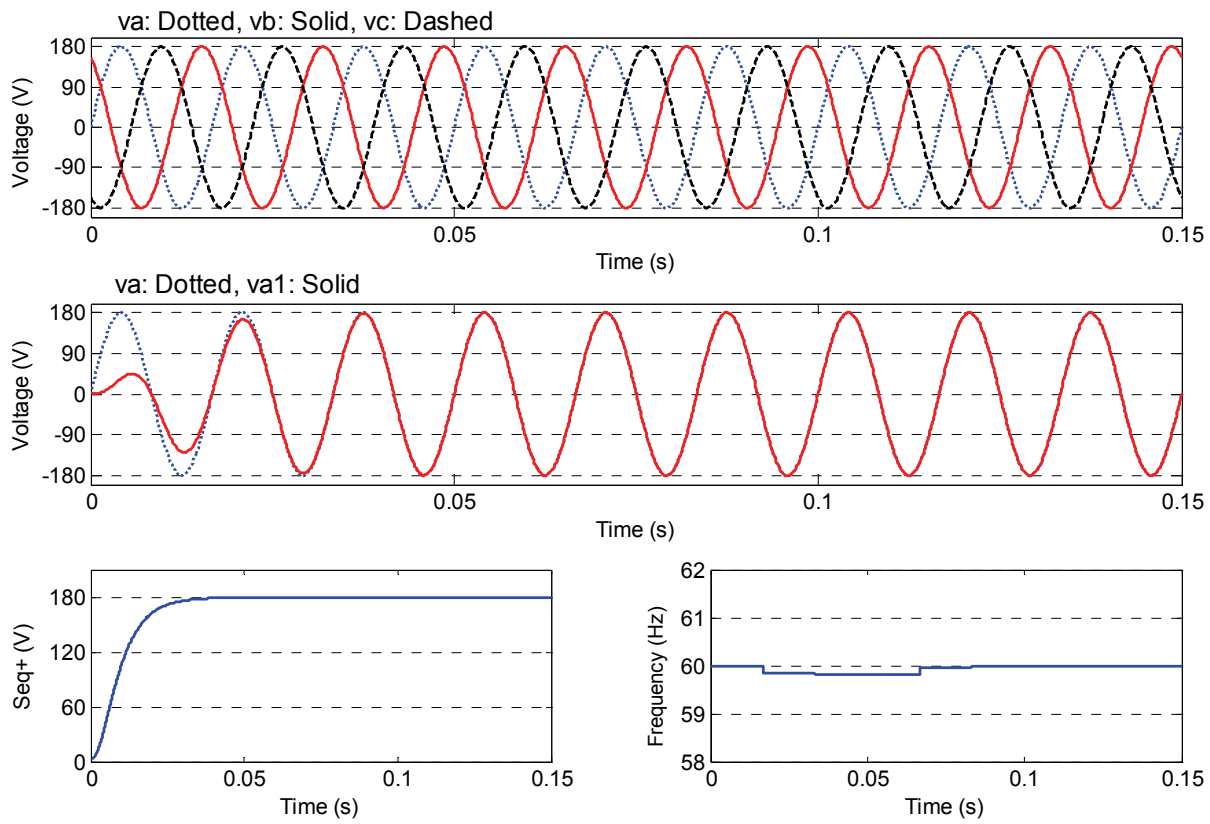

Fig. 6. KF-3 $\phi$ (Case 1): Sinusoidal and balanced input voltages $\left(127 \mathrm{Vrms}, 60 \mathrm{~Hz}, 0^{\circ}\right.$ - phase a), and KF outputs - va1, Seq+ and $f_{1}$.
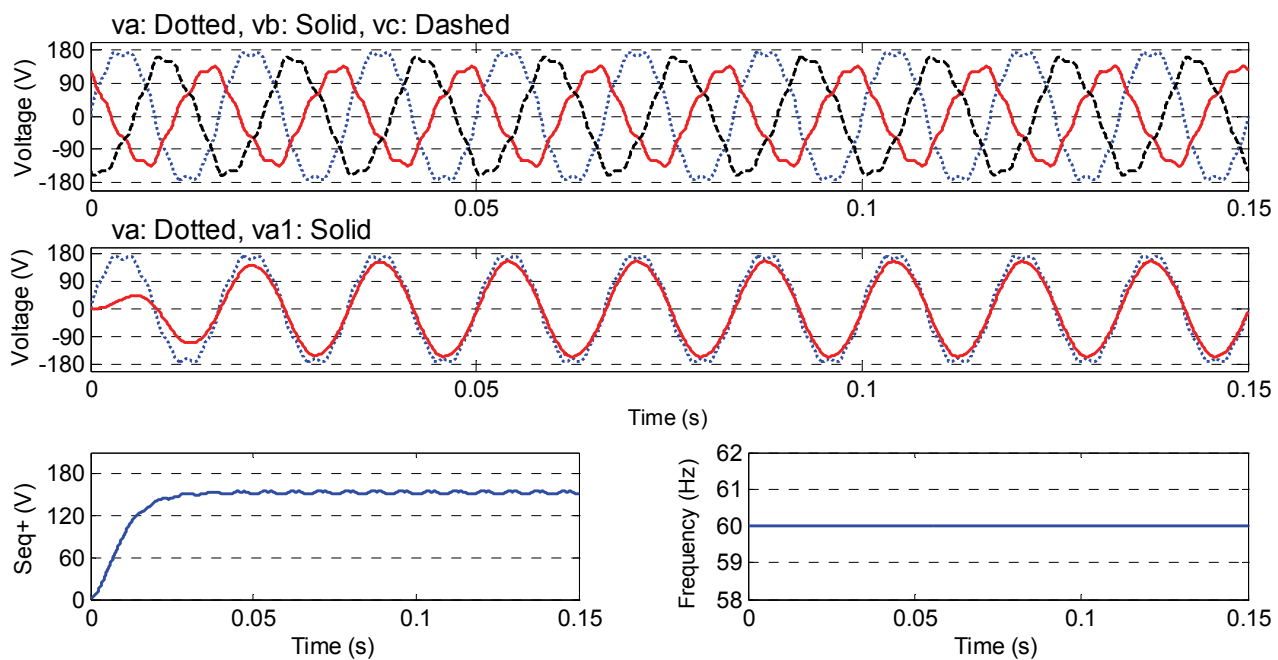

Fig. 7. KF-3 $\phi$ (Case 2): filter response with unbalanced and distorted three-phase input voltages.

Fig. 8 and 9 show the performance of the KF-3 $\phi$ when the power system voltages present an abrupt amplitude and frequency variations. In the case of amplitude variation (Fig. 8 ), the 
filtered voltages converge in 1 cycle while the frequency practically does not alter. In case of frequency variation, $f_{1}$ stabilizes in about 9 cycles.
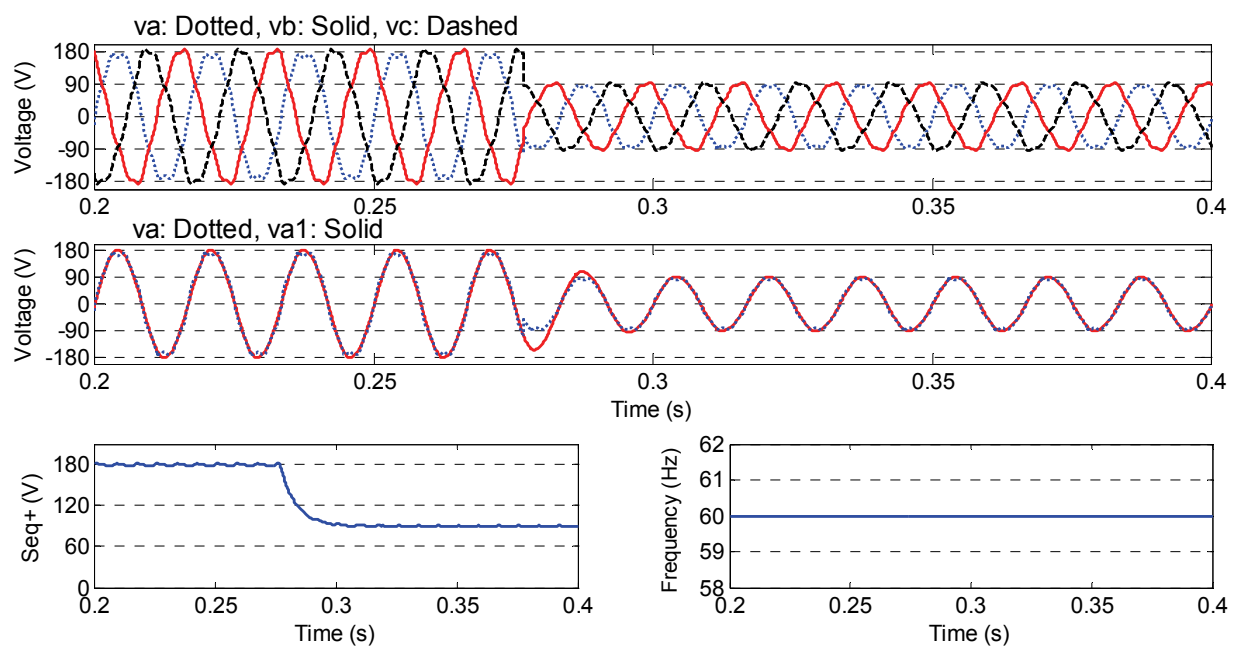

Fig. 8. KF-3 $\phi$ (Case 3): outputs with distorted voltages and a three-phase voltage sag.
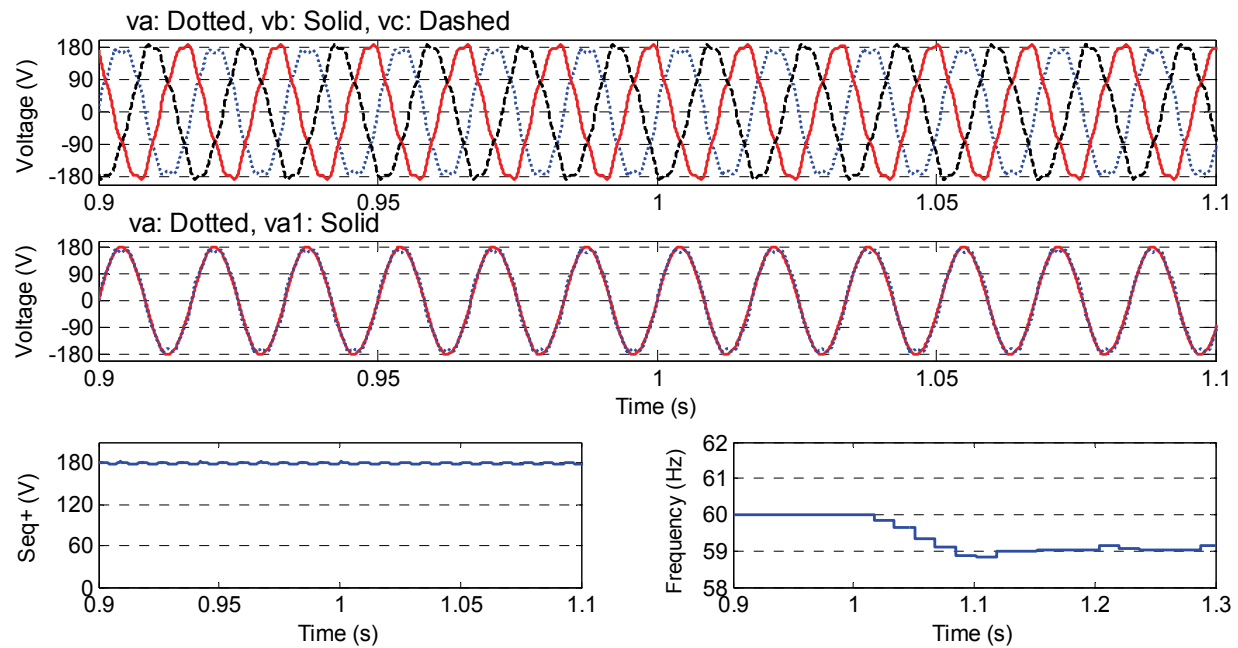

Fig. 9. KF-3 $\phi$ outputs with distorted voltages and abrupt frequency deviation.

In order to demonstrate the influence of the matrices $G G^{T}$ and $H H^{T}$, the conditions of Case 1 were simulated considering the following parameters:

$$
G G^{T}=\left[\begin{array}{cccc}
0.1 & 0 & 0 & 0 \\
0 & 0.1 & 0 & 0 \\
0 & 0 & 0.1 & 0 \\
0 & 0 & 0 & 0.1
\end{array}\right] \text { e } H H^{T}=\left[\begin{array}{ccc}
250 & 0 & 0 \\
0 & 250 & 0 \\
0 & 0 & 250
\end{array}\right]
$$


Fig. 10 shows the performance of the KF in such condition. Comparing to Fig. 6, note that in this case the KF convergence is faster than in the previous configuration.
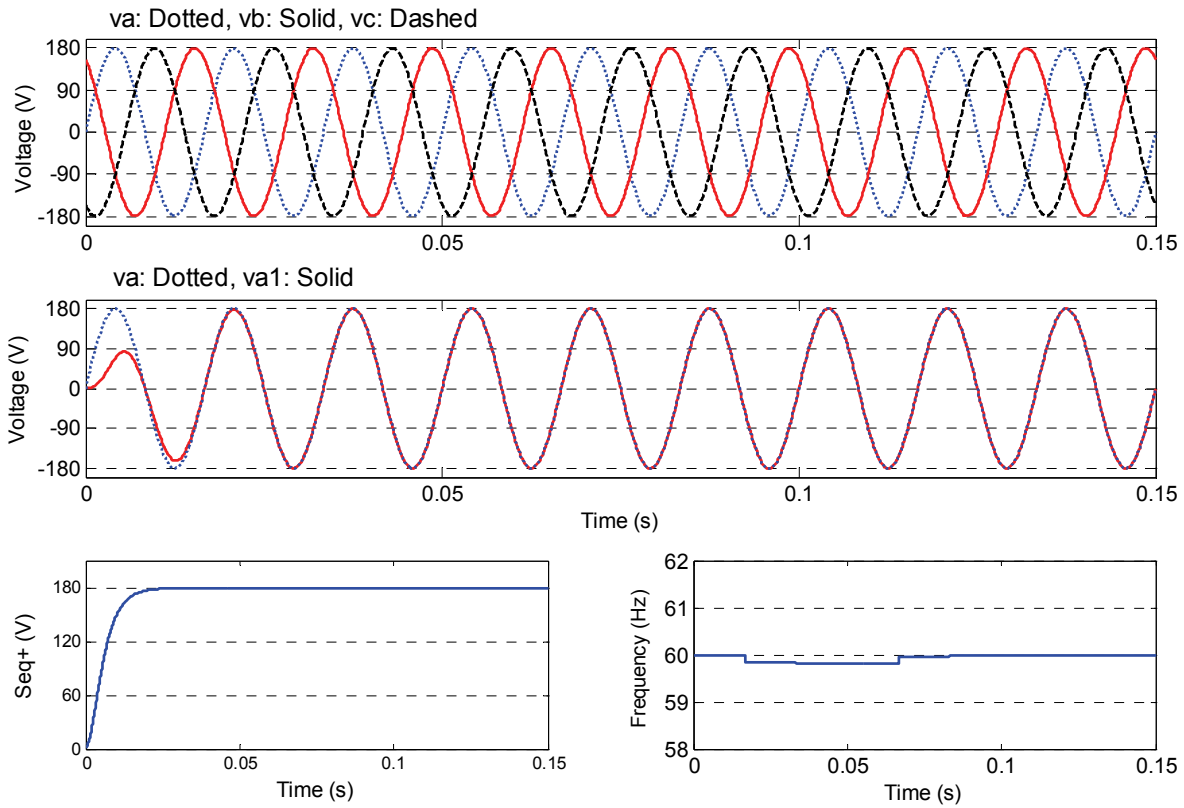

Fig. 10. KF-3 $\phi$ (Case 1): Sinusoidal and balanced input voltages and KF outputs considering a different configuration in matrices $\boldsymbol{H}$ and $\boldsymbol{G}$.

\subsection{Experimental results}

For the purpose of evaluating the KF in practical real-time applications, the single-phase model was implemented in a high performance acquisition system and the three-phase model was implemented in a fixed point digital signal processor (DSP). The obtained results are presented in next sections.

\subsubsection{High performace acquisition system}

The single-phase algorithm was tested in a data acquisition and processing system based on the concept of virtual instrumentation (Moreira et al., 2005). The experimental apparatus was composed by an eight-channel simultaneous acquisition board with 16-bit AD converter (PCI-6143 from National Instruments - NI) with maximum frequency of $200 \mathrm{kHz}$. The analog signals were measured by current and voltage Hall-effect sensors (LV-25P and LA-55P from LEM) and the computational part was implemented in a Pentium 4 desktop with LabView 7.1 software (National Instruments). The voltages were generated by a programmable three-phase generator from California Instruments, model 4500iL.

Initially, the KF-1 $\phi$ algorithm was tested for different voltage conditions. In the uppermost graphic of Fig. 11, one has a sinusoidal $127 \mathrm{Vrms}, 60 \mathrm{~Hz}$ input voltage with $10 \%$ of $3^{\text {rd }}, 5^{\text {th }}$ and $7^{\text {th }}$ harmonic distortion. In the middle graphic, one has the estimated and filtered voltage v1. In the bottom, the estimated fundamental frequency $f_{1}$ can be seen. 

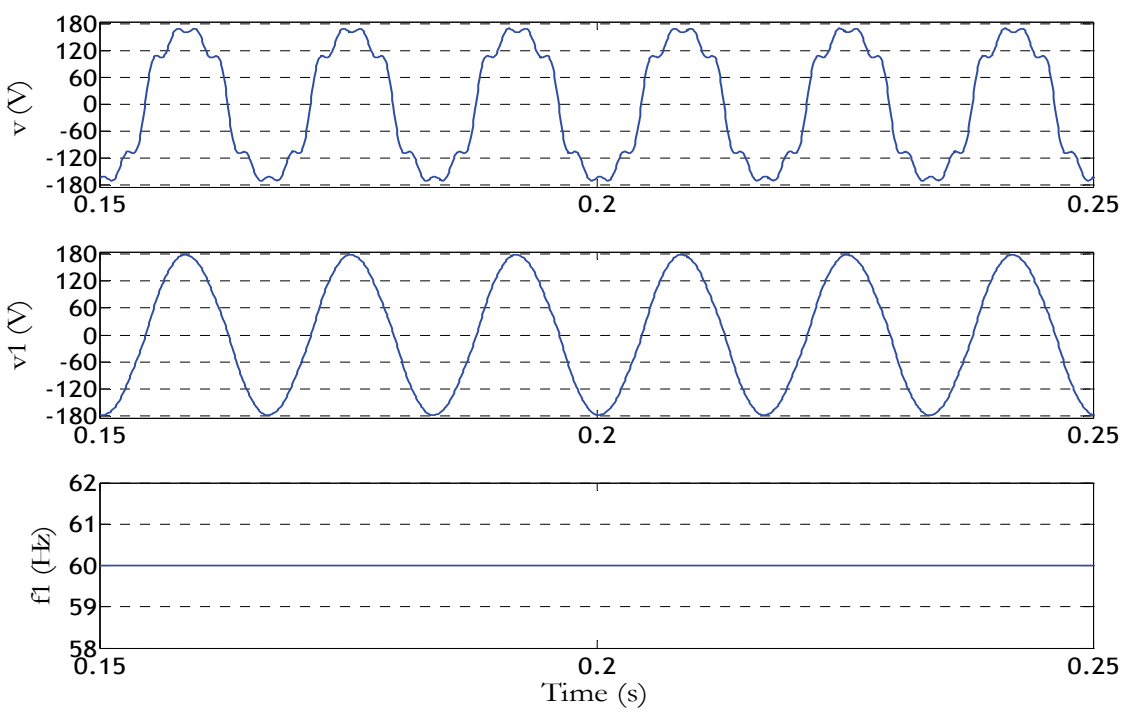

Fig. 11. KF-1申: Top - input voltage $(127 \mathrm{Vrms}, 60 \mathrm{~Hz})$, with $10 \%$ of $3^{\text {rd }}, 5^{\text {th }}$ and $7^{\text {th }}$ harmonic distortion; middle - fundamental component and bottom - fundamental frequency estimated by the KF.

In Fig. 12, the input voltage suffers a voltage sag of $50 \%$, but despite that, the algorithm manages to converge in about one cycle. In Fig. 13, the amplitude remains constant but there is an abrupt change in the fundamental frequency from 60 to $59 \mathrm{~Hz}$. There is no change in the filtered voltage, but the frequency stabilizes in about 10 cycles.
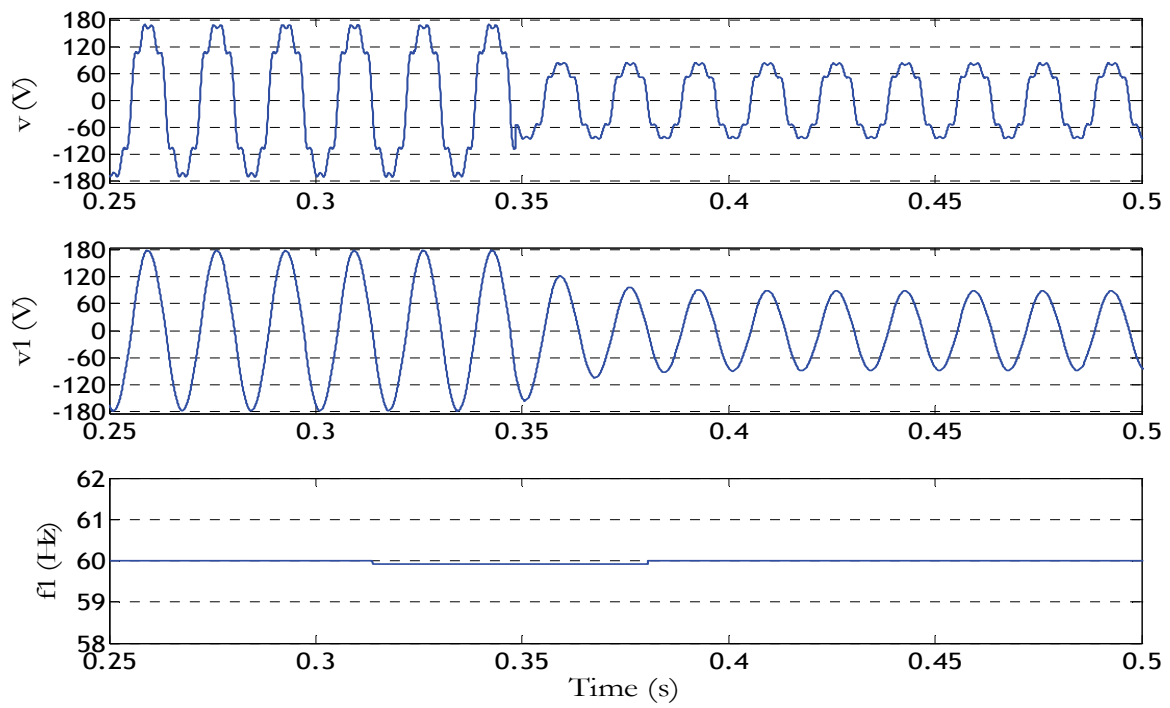

Fig. 12. KF-1ф: Performance of the KF output under 50\% voltage sag. 

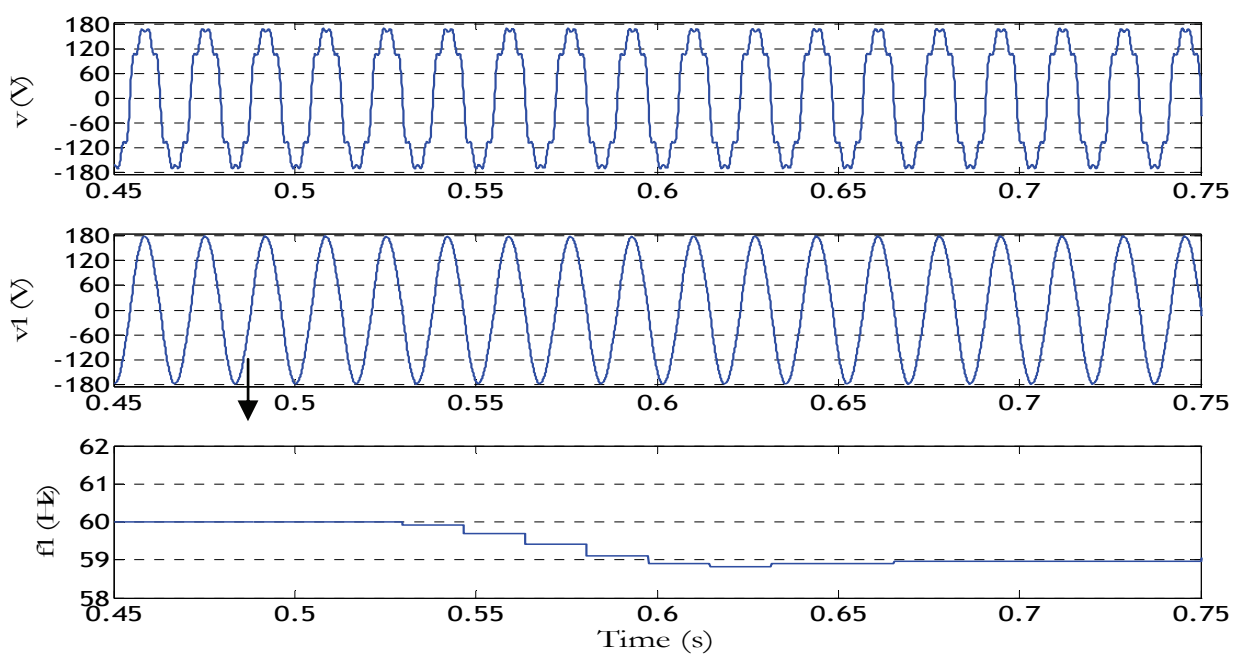

Fig. 13. KF-1 $\phi$ : Performance of the KF output under an abrupt frequency deviation (from 60 to $59 \mathrm{~Hz}$ ).

\subsubsection{2-bits fixed point DSP}

In order to demonstrate that the KF can be implemented even in fixed-point discrete systems, the three-phase model was implemented in a fixed-point 32-bit DSP, from Texas Instruments (TMS320F2812). The sampling frequency was set to $12 \mathrm{kHz}$.

Fig. 14 shows the three-phase input voltages, which became distorted $\left(20 \%\right.$ of $3^{\text {rd }}$ and $10 \%$ of $5^{\text {th }}$ harmonics and each phase) after a $50 \%$ voltage sag. Considering just one of the phase voltages, Fig. 15 shows the convergence of the KF estimated fundamental component. Note that it converges in less than 2 fundamental cycles. Observe that the magnitudes in both figures are normalized by the digital to analog (DA) converter applied to reconstruct the KF output and the digitalized input voltages.

\section{Conclusion}

This chapter has discussed the main characteristics of the Kalman Filter and possible applications in the areas of power electronics and power systems. Since a great number of this applications are based on the identification of the fundamental voltage and/or current signals, it was demonstrated how the KF can be applied to estimate the fundamental component from a distorted signal (and/or an unbalanced set of signals in case of threephase systems) like those present in real power system. The filter was designed by adopting a stochastic state-space model for the power system voltage, what is a very reasonable hypothesis. The performance of the zero-crossing detection method, based on the estimated voltage, was shown to be very effective as a way to calculate the fundamental frequency $f_{1}$, even in the presence of harmonic distortion.

Complex matrix calculations are not a concern here because their dimensions never exceed two, in the single-phase case (and four, in the three-phase case). It makes possible to do calculations elementwise. In the three-phase case, the algorithm also estimates the mean- 


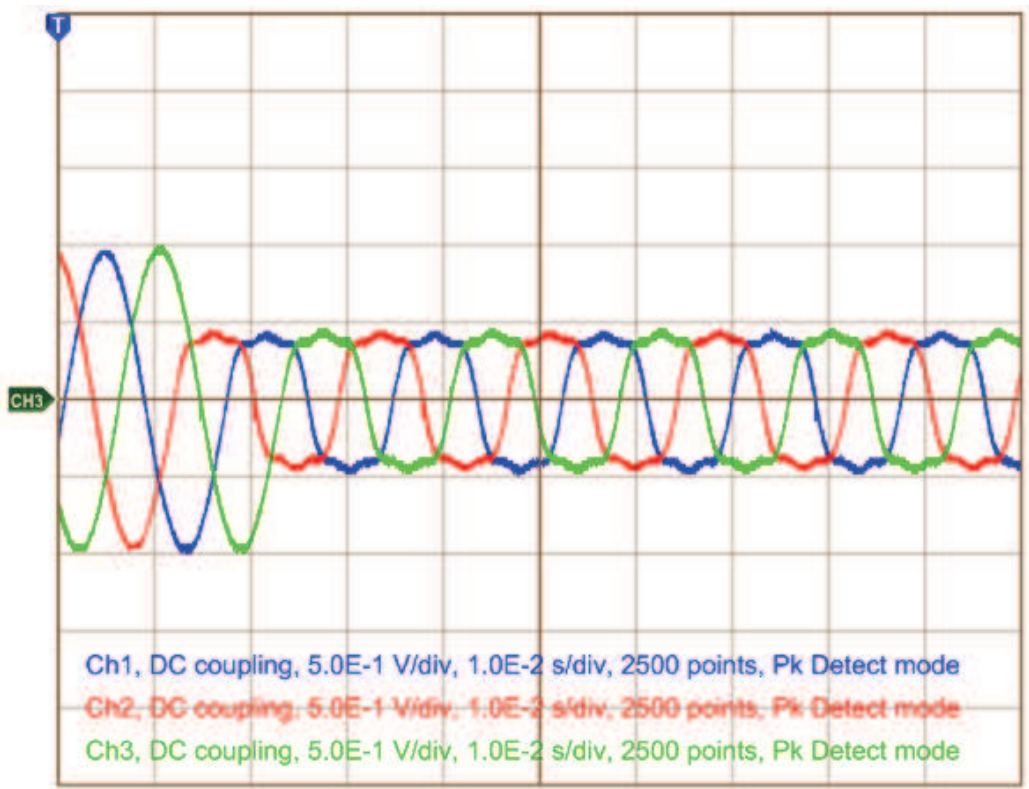

Fig. 14. KF-3 $\phi$ : DSP input voltages considering a $50 \%$ voltage sag and $20 \%$ of $3^{\text {rd }}$ and $10 \%$ of $5^{\text {th }}$ harmonics and each phase.

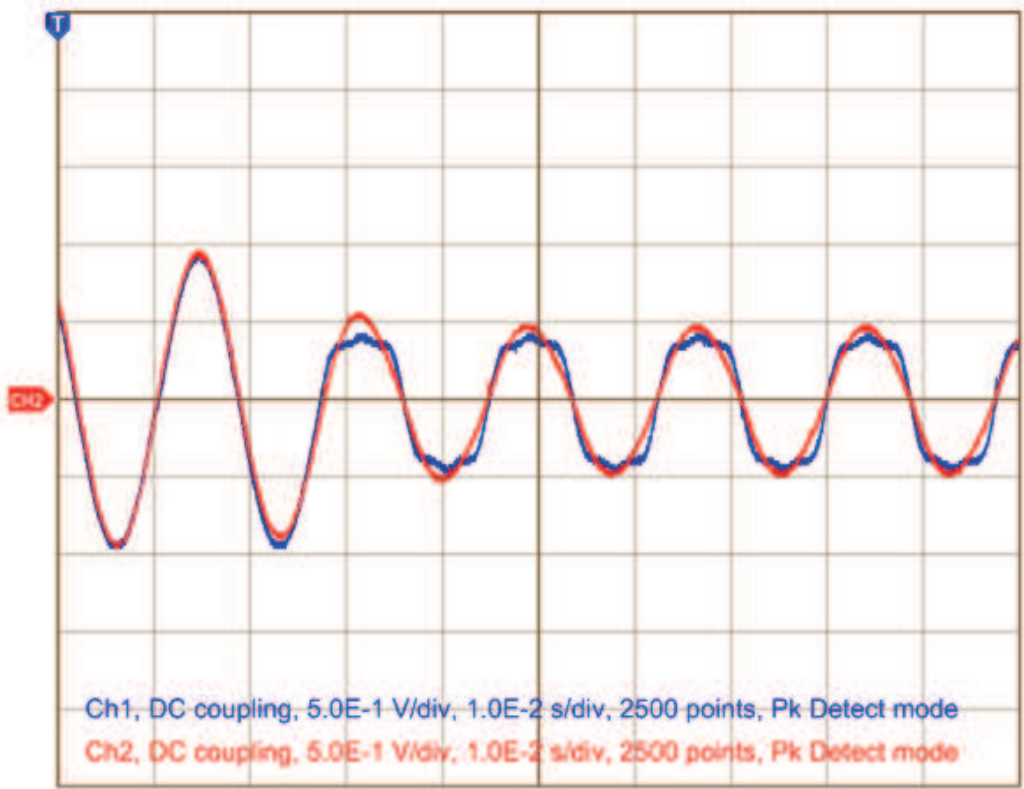

Fig. 15. KF-3 $\phi$ : Fundamental component estimation after the $50 \%$ voltage sag, with corresponding voltage distortion (for one of the phases). 
amplitude in the presence of unbalanced voltages, what could be used, in some cases, in place of a positive-sequence detector (Padua et al., 2005). It was also shown that, setting adequate values to $H$ and $G$, the performance of the three-phase could be better than the single-phase case.

Simulated and experimental results illustrate the suitable performance of the KF (single and three-phase models) in different conditions and tuning. So the proposed models are interesting alternatives for power systems and power electronics applications, even if realtime and fixed-point implementations are required.

Comparing with other synchronization algorithms, like those in (Kaura \& Blasko, 1997; Zhan et al., 2001 ; McGrath et al., 2005 ; Cardoso et al, 2006; Mostata, 2007), as to say the PLL-based and the DFT-based, one can say that the proposed Kalman filter based algorithm is 1) so precise in steady-state as the others two; 2) as fast and sensible to voltage distortions as the PLL-based and 3) computationally simpler than other Kalman-based algorithms presented in literature.

It is important to point out that no matter how complex the detection algorithm is, there is always a compromise between precision (or in a wide sense, robustness) and rapidity of the response. The designer should thus know how to adjust $H$ and $G$ matrices in the most convenient way for the application in hand. Besides, the computational complexity can be a major concern, as in real-time analysis and control.

Considering future works, the author's intend to modify the three-phase KF in order to obtain the fundamental positive sequence components in the presence of phase-angle asymmetries, since in this case, equation (8) does not represent correctly such information.

\section{References}

Andria, G. \& Salvatore, L. (1990). Inverter Drive Signal Processing Via DFT and EKF, IEE Proceedings Electric Power Applications, Vol. 137, No. 2, (March 1990), pages (111 119), ISSN 0143-7038.

Bollen, M. H. J. (2000). Understanding power quality problems: Voltage Sags And Interruptions. IEEE Press Series on Power Engineering, P. M. Anderson Series Editor, New York USA.

Bolognani, S.; Zigliotto, M. \& Zordan, M. (2001). Extended-Range PMSM Sensorless Speed Drive Based on Stochastic Filtering, IEEE Transactions on Power Electronics, Vol. 16, No. 1, (January 2001), pages (110-117), ISSN 0885-8993.

Cardoso, R.; de Camargo, R. F.; Pinheiro, H. \& Gründling, H. A. (2006). Kalman Filter Based Synchronisation Methods, The 37th IEEE Power Electronics Specialists Conference PESC, pp. 1-7, ISBN 0-7803-9716-9, June 2006, Jeju Korea.

Chien-Hung Huang; Chien-Hsing Lee; Kuang-Jung Shih; Yaw-Juen Wang (2008). Frequency Estimation of Distorted Power System Signals Using a Robust Algorithm, IEEE Transactions on Power Delivery, Vol. 23, No. 1, (January 2008), pages (41-51), ISSN 0885-8977.

Clements, M. P. \& Hendry, D. F. (1998). Forecasting Economic Time Series, Cambridge University Press, ISBN 0521632420, United Kingdom.

Colón, D. \& Pait, F. M. (2004). Geometry of Adaptive Control: Optimization and Geodesics, International Journal of Adaptive Control and Signal Processing, Vol. 18, No. 4, (May 2004), pages (381 - 392), ISSN 0890-6327. 
Dash, P. K. \& Chilukuri, M. V. (2004). Hybrid S-transform and Kalman Filtering Approach for Detection and Measurement of Short Duration Disturbances in Power Networks, IEEE Transaction on Instrumentation and Measurement, Vol. 53, No. 2, (April 2004), pages (588-596), ISSN 0018-9456.

Davis, M. H. A. \& Vinter, R. B. (1985). Stochastic Modelling and Control, Monographs on Statistics and Applied Probability 24, Chapman and Hall, ISBN MR86f:93118, London/New York USA.

Farghal, S. A.; Kandil, M. S. \& Elmitwally, A. (2002). Quantifying Electric Power Quality Via Fuzzy Modelling and Analytic Hierarchy Processing, IEE Proceeding Generation, Transmission and Distribution, Vol. 149, No. 1, (January 2002), pages (44-49), ISSN 1350-2360.

Ferrero, A. ; Peretto, L. \& Sasdelli, R. (1998). Revenue metering in the presence of distortion and unbalance: myths and reality, Proceedings of the IEEE International Conference on Harmonics and Quality of Power, pp. 42-47, ISBN 0-7803-7671-4, Greece.

Girgis, A. A. \& Brown, R. G. (1981). Application of Kalman Filtering in Computer Relaying, IEEE Transactions on Power Apparatus and Systems, Vol. PAS-100, No. 7, (July 1981), pages (3387-3397), ISSN 0018-9510.

Girgis, A. A. (1982). A New Kalman Filtering Based Digital Distance Relay, IEEE Transactions on Power Apparatus and Systems, Vol. PAS-101, No. 9, (September 1982), pages (3471-3480), ISSN 0018-9510.

Gonzalez, M.; Cardenas, V. \& Alvarez, R. (2006). Detection of Sags, Swells, and Interruptions Using the Digital RMS Method and Kalman Filter with Fast Response, The 32nd Conference of the IEEE Industrial Electronics Society IECON, pp. 2249-2254, ISBN: 1-4244-0391-X, November 2006, Paris, France.

IEEE Trial-Use Standard Definitions for the Measurement of Electric Power Quantities Under Sinusoidal, Nonsinusoidal, Balanced or Unbalanced Conditions, IEEE Standard 1459-2000, (June, 2000), ISBN 0-7381-1963-6.

Kalman, R. E. (1960). A New Approach to Linear Filtering and Prediction Problems, Transaction of the ASME - Journal of Basic Engineering, 82 Seires D, (March 1960), pagues (35-45), ISSN 0021-9223.

Kaura, V. \& Blasko, V. (1997). Operation of a Phase Locked Loop System under Distorted Utility Conditions, IEEE Transaction on Industry Applications, Vol. 33, No. 1, (January/February 1997), pages (58-63), ISSN 0093-9994.

Kwan, K. H.; So, P. L. \& Chu, Y. C. (2005). Unified Power Quality Conditioner for Improving Power Quality using MVR with Kalman Filters, The 7th International Power Engineering Conference IPEC, vol. 2, pp. 980-985, ISBN 981-05-5702-7, December 2005, Singapore.

Li-Cheng Zai; DeMarco, C.L. \& Lipo, T.A. (1992). An Extended Kalman Filter Approach to Rotor Time Constant Measurement in PWM Induction Motor Drives, IEEE Transactions on Industry Applications, Vol. 28 , No. 1, (January/February 1992), pages (96-104), ISSN: 0093-9994.

Marafão, F. P.; Deckmann, S. M. \& Marafão, J. A. G. (2002). Power Factor Analysis under Nonsinusoidal and Unbalanced Systems, The 10th International Conference on Harmonics and Quality of Power ICHQP, pp. 266-271, ISBN 0-7803-7671-4, October 2002, Rio de Janeiro, Brazil. 
Marafão, F. P. et al, (2008). Multiloop Controller and Reference generator for a Dynamic Voltage Restorer Implementarion, Proceedings of the 13th IEEE International Conference on Harmonics and Quality of Power ICHQP, October 2008, Australia.

McGrath, B. P.; Holmes, D. G.; \& Galloway, J. (2005). Power Converter Line Synchronization Using a Discrete Fourier Transform (DFT) Based on a Variable Sample Rate, IEEE Transactions on Power Electronics, Vol. 20, No. 4, (July 2005), pages (877-844), ISSN 0885-8993.

Mir, M. \& Mccleer, P. J. (1984). Simulation Methods for Optimum Performance Estimation of Analog and Computer Impedance Relays, IEEE Transactions on Power Apparatus and Systems, Vol. PAS-103, No 6, (June 1984), pages (1147-1154), ISSN 0018-9510.

Mohamed A.; Abu-El-Magd \& Naresh K. S. (1981). Two New Algotihms for On-Line Modelling and Forecasting of the Load Demand of a Multinode Power System, IEEE Transactions on Power Apparatus and Systems, Vol. PAS-100, No. 7 (July 1981), pages (3246-3253), ISSN 0018-9510.

Moreira, A. C.; Deckmann, S. M.; Marafão, F. P.; Lima, E. G.; \& Bini, M. A. (2005). Virtual Instrumentation Applied to the Implementation of IEEE STD 1459-2000 Power Definitions, The IEEE 36th Power Electronics Specialists Conference PESC, pp. 17121718, ISBN 0-7803-9033-4, June 2005, Recife Brazil.

Moreno, V. M.; Lopez, A. P. \& Garcias, R. I. D. (2004). Reference Current Estimation under Distorted Line Voltage for Control of Shunt Active Power Filters, IEEE Transactions on Power Electronics, Vol. 19, No. 4, (July 2004), pages (988-994), ISSN: 0885-8993.

Moreno, V. M.; Liserre, M.; Pigazo, A. \& Dell'Aquila, A. (2007). A Comparative Analysis of Real-Time Algorithms for Power Signal Decomposition in Multiple Synchronous Reference Frames, IEEE Transactions on Power Electronics, Vol. 22, No. 4, (July 2007), pages (1280-1289), ISSN 0885-8993.

Mostafa, M. A. (2003). Kalman Filtering Algorithm for Electric Power Quality Analysis: Harmonics and Voltage Sags Problems. The IEEE Large Engineering Systems Conference on power Engineering LESCOPE, pp. 110-119, ISBN 0-7803-7863-6, May 2003, Montreal, Canada.

Oppenheim, A. V. \& Schafer, R. W. (1999). Discrete-Time Signal Processing. (2nd Edition), Prentice Hall, ISBN 013216292X, New Jersey, USA.

Pádua, M. S.; Deckmann, S. M. \& Marafão, F. P. (2005). Frequency-Adjustable Positive Sequence Detector for Power Conditioning Applications, IEEE 36th Power Electronics Specialists Conference, pp. 1928-1934, ISBN 0-7803-9033-4, Recife, Brazil.

Pádua, M. S.; Deckmann, S. M.; Sperandio, G. S. ; Marafão, F. P. \& Colón, D. (2007). Comparative Analysis of Synchronization Algorithmos based on PLL, RDFT and Kalman Filter, Proceedings of the IEEE International Symposium on Industrial Electronics ISIE, June 2007, Vigo, Spain.

Pádua, M. S.; Deckmann, S. M.; Marafão, F. P. \& Colón, D. (2007a). Simplified Models of Kalman Filter for Fundamental Frequency, Amplitude and Phase Angle Detection, Proceedings of the Brazilian Power Electronics Conference (COBEP), Blumenau Brazil.

Papoulis, A. (1991). Probability, Random Variables, and Stochastic Processes, MacGraw-Hill Series in Electrical Engineering, Comunnication and signal processing, Third Edition, MacGraw-Hill Companies, ISBN 0070484771, USA. 
Park, J. H. ; Park, Y. M. \& Lee, K. Y. (1991). Composite Modeling for Adaptive Short-Term Load Forecasting, IEEE Transactions on Power Systems, Vol. 6. No. 2, (May 1991), pages (450-457), ISSN 1558-0679.

Peng. F. Z. (2001). Harmonic Sources and Filtering Approaches. IEEE Industry application Magazine. Vol. 7, No. 4, (July/August 2001), pages (18-25), ISSN 1077-2618.

Pietrzak-David, M.; de Fornel, B.; Lima, A. M. N. \& Jelassi, K. (1992). Digital Control of an Induction Motor Drive by a Stochastic Estimator and Airgap Magnetic Flux Feedback Loop, IEEE Transactions on Power Electronics, Vol. 7 No. 2, (April 1992), pages (393 - 403), ISSN 0885-8993.

Rosendo, J. A.; Bachiller, A. \& Gomez, A. (2007). Application of Self-Tuned Kalman Filters to Control of Active Power Filters, The IEEE Power Tech, pp. 1262-1265, ISBN: 978-14244-2189-3, July 2007, Lausanne Switzerland.

Sachdev, M. S.; Wood, H. C. \& Johnson, N. G. (1985). Kalman Filtering Applied to Power System Measurements for Relaying, IEEE Transactions on Power Apparatus and Systems, Vol. PAS-104, No. 12, pages (3565-3573), ISSN 0018-9510.

Satry, S. \& Bodson, M. (1989). Adaptive Control: Stability, Convergence, and Robustness, Prentice-Hall, ISBN 0-13-004326-5, USA.

Song, K. B.; Ha, S. K.; Park, J. W.; Kweon, D. J. \& Kim, K. H. (2006). Hybrid Load Forecasting Method With Analysis of Temperature Sensitivities, IEEE Transactions on Power Systems, Vol. 21, No. 2, (May 2006), pegas (869-876), ISSN 1558-0679.

Styvaktakis, E.; Bollen, M. H. J. \& Gu, I. Y. H. (2002). Expert System for Classification and Analysis of Power System Events, IEEE Transactions on Power Delivery, Vol. 17, No. 2, (April 2002), pages (423 - 428), ISSN 0885-8977.

Zhan, C.; Fitzer, C.; Ramachandaramurthy, V. K.; Arulampalam, A.; Barnes, M. \& Jenkins, N. (2001). Software Phase-Locked Loop Applied to Dynamic Voltage Restorer (DVR), IEEE Power Engineering Society Winter Meeting, pp. 1033-1038, ISBN: 0-78036672-7, January/February 2001, Columbus USA.

Yeh, H. G. (1990). Real-Time Implementation of a Narrow-Band Kalman Filter With a Floating-Point Processor DSP32, IEEE Transactions on Industrial Electronics, Vol. 37, No. 1, (February 1990), pages (13-18), ISSN 0278-0046.

Wade, S.; Dunnigan, M. W. \& Williams, B. W. (1997). Modeling and simulation of induction machine vector control with rotor resistance identification, IEEE Transactions on Power Electronics, Vol. 12, No. 3, (May 1997), pages (495-506), ISSN 0885-8993.

Wiltshire, R. A.; Ledwich, G. \& O'Shea, P. (2007). A Kalman Filtering Approach to Rapidly Detecting Modal Changes in Power Systems, IEEE Transactions on Power Systems, Vol. 22, No. 4, (November 2007), pages (1698- 1706), ISSN 1558-0679.

Wong, W. S. \& Yau, S. S. T. (1998), The Estimation Algebra of Nonlinear Filtering Systems, In : Mathematical Control Theory, pages 33-65, Springer, ISBN 0387983171, USA.

Woxd, H. C.; Johnson, N. G. \& Sachdev, M. S. (1985). Kalman Filtering Applied to Power System Measurements Relaying, IEEE Transactions on Power Apparatus and Systems, Vol. PAS-104, No. 12, (December 1985), pages (3565-3573), ISSN 0018-9510. 


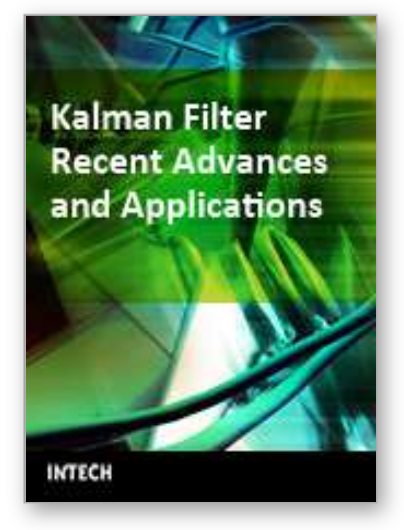

\section{Kalman Filter Recent Advances and Applications \\ Edited by Victor M. Moreno and Alberto Pigazo}

ISBN 978-953-307-000-1

Hard cover, 584 pages

Publisher InTech

Published online 01, April, 2009

Published in print edition April, 2009

The aim of this book is to provide an overview of recent developments in Kalman filter theory and their applications in engineering and scientific fields. The book is divided into 24 chapters and organized in five blocks corresponding to recent advances in Kalman filtering theory, applications in medical and biological sciences, tracking and positioning systems, electrical engineering and, finally, industrial processes and communication networks.

\section{How to reference}

In order to correctly reference this scholarly work, feel free to copy and paste the following:

Fernando P. Marafão, Diego Colón, Marcelo S. de Padua and Sigmar M. Deckmann (2009). Kalman Filter on Power Electronics and Power Systems Applications, Kalman Filter Recent Advances and Applications, Victor M. Moreno and Alberto Pigazo (Ed.), ISBN: 978-953-307-000-1, InTech, Available from:

http://www.intechopen.com/books/kalman_filter_recent_adavnces_and_applications/kalman_filter_on_power_ electronics_and_power_systems_applications

\section{INTECH}

open science | open minds

\section{InTech Europe}

University Campus STeP Ri

Slavka Krautzeka 83/A

51000 Rijeka, Croatia

Phone: +385 (51) 770447

Fax: +385 (51) 686166

www.intechopen.com

\section{InTech China}

Unit 405, Office Block, Hotel Equatorial Shanghai

No.65, Yan An Road (West), Shanghai, 200040, China

中国上海市延安西路65号上海国际贵都大饭店办公楼 405 单元

Phone: +86-21-62489820

Fax: $+86-21-62489821$ 
(C) 2009 The Author(s). Licensee IntechOpen. This chapter is distributed under the terms of the Creative Commons Attribution-NonCommercialShareAlike-3.0 License, which permits use, distribution and reproduction for non-commercial purposes, provided the original is properly cited and derivative works building on this content are distributed under the same license. 